\title{
A fertility restorer gene, $R f 4$, widely used for hybrid rice breeding encodes a pentatricopeptide repeat protein
}

\author{
Tomohiko Kazama and Kinya Toriyama*
}

\begin{abstract}
Background: Uncontrolled expression of a certain mitochondrial gene often causes cytoplasmic male sterility (CMS) in plants. This phenotype is prevented by the presence of a fertility restorer $(R f)$ gene in the nuclear genome. Such CMS/Rf systems have been successfully used for breedings of $F_{1}$ hybrid cultivars. In rice, approximately $99 \%$ of $F_{1}$ hybrid cultivars have been developed using a wild abortive type of CMS (WA-CMS) and its Rf genes. Recently, a newly identified mitochondrial gene, orf352, was reported as a WA-CMS-causing gene.

Findings: We cloned and functionally characterized Rf4, a major Rf gene for WA-CMS. We revealed that Rf4 encoded a pentatricopeptide repeat-containing protein and reduced the orf352-containing transcripts, thereby restoring pollen fertility.

Conclusions: Through a map-based cloning, we have independently identified an allele of a recently reported Rf4 gene and demonstrated that the fertility restoration is controlled sporophytically.
\end{abstract}

Keywords: Cytoplasmic male sterility; Fertility restorer; Rice

\section{Findings}

A wild abortive (WA)-type CMS has been almost exclusively used for breeding three-line hybrid rice and contributes to $10 \%$ of the total rice cultivated area worldwide (Li et al. 2007; Barclay 2010). Because of the great impact of WA-type CMS on agriculture, many studies have attempted to elucidate the CMS-causing gene in WA mitochondria and to determine the fertility restorer genes for WA-CMS. In 2013, a mitochondrial orf352 (WA352) gene that confers WA-CMS was discovered; this gene encodes 352-amino-acids protein (Luo et al. 2013). We also found a sequence variant of orf352 in an RT102 CMS line derived from O. rufipogon (Okazaki et al. 2013). However, the $R f$ genes in nuclear genome have not yet been cloned, although two major $R f$ genes, $R f 3$ and $R f 4$, have been mapped on the chromosomes 1 and 10, respectively (Lu et al. 1997; Yao et al. 1997; Tan et al. 2008; Jing et al. 2001; Ahmadikhah and Karlov 2006; Ngangkham et al. 2010; Suresh et al. 2012). In this study, we report the cloning of

\footnotetext{
* Correspondence: torikin@bios.tohoku.ac.jp

Graduate School of Agricultural Science, Tohoku University, 1-1

Tsutsumidori-Amamiyamachi, Aoba-ku, Sendai 981-8555, Japan
}

Rf4. We also showed that the cloned Rf4 reduced the orf352-containing transcripts and restored pollen fertility.

To identify the Rf4 gene for WA-CMS, we performed map-based cloning of $R f 4$ using a cultivar IR24 (Additional file 1: "Methods"), because this cultivar is known to be a strong restorer line for WA-CMS (Jing et al. 2001). We delimited the Rf4 candidate region between two SSR markers, SSR1045 and AT801, that corresponded to a 213-kb region of Nipponbare genome (Additional file 2: Table S1). While we were conducting the fine mapping, Ngangkham et al. (2010) reported that Rf4 was located in a region between RM6737 and RM6100 with a distance of $104 \mathrm{~kb}$ in the Nipponbare genome, which further narrowed down the candidate region. We isolated a bacterial artificial chromosome (BAC) clones covering the corresponding region from IR24 genomic libraries (Figure 1) and determined their nucleotide sequences (Additional file 1: "Methods"). Because the presence of Rf4 reduced the orf352-containing transcripts in the mitochondria, we identified the candidate gene according to the following two criteria, (i) it would encode a protein whose function is related to RNA metabolism, 


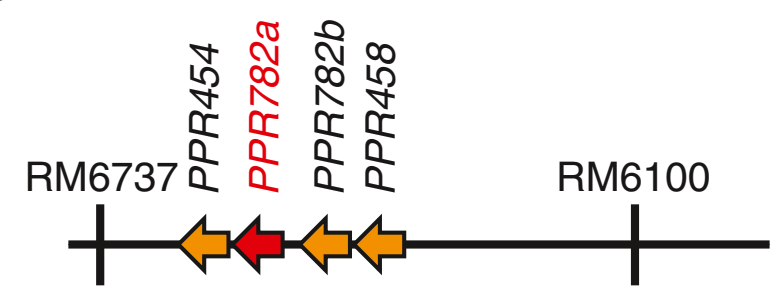

Figure 1 Candidate genes present in the IR24 BAC clone. Candidate genes and SSR markers in the IR24 BAC clone are indicated.

and (ii) it would encode a mitochondrial-targeting protein. The candidate genes that fulfilled the criteria were four new pentatricopeptide repeat (PPR)-encoding genes, PPR454, PPR782a, PPR782b, and PPR458 (Figure 1). These genes were named on the number of amino acids that they encoded. PPR proteins are, in general, known to be involved in RNA regulation in the mitochondria and plastids (Schmitz-Linneweber and Small 2008). We obtained genomic fragments containing PPR454, PPR782a, PPR782b, or PPR458 from the IR24 BAC clone (Additional file 1: "Methods"; Additional file 3:
Figure S1). We introduced each genomic fragment into a WA-CMS line, WAA, which carries a Taichung 65 nuclear background, and obtained at least twelve transgenic lines (Additional file 4: Figure S2).

The anthers of WA-CMS are milky white, slender, and stunted (Additional file 4: Figure S2) and contain shrunken pollen grains lacking starch accumulation ability, because of which they are not stained with $1 \%$ potassium iodide (Figure 2a). In contrast, anthers of fertile Taichung 65 are yellow and engorged and contain darkly stained pollen grains. In four of the thirteen transgenic plants with PPR782a, restorations of anther and pollen development and starch accumulation in pollen grains were observed (Figure 2a; Additional file 4: Figure S2). The percentage of stainable pollen grains (pollen stainability) was $48 \%$ for plant Nos. 9,10 , and 12 , and $79 \%$ for plant No. 13 (Figure 2b). Especially, one of the plants (No. 13) showed $47 \%$ seed setting rate (Figure 2c). Restorations of anther and pollen development were not observed in the remaining nine plants. Introduction of three other genomic fragments, which contained PPR782b, PPR454, or PPR458, did not recover the anther and pollen morphology (Additional file 4: Figure S2), and resulted in $0 \%$ of

\section{a}
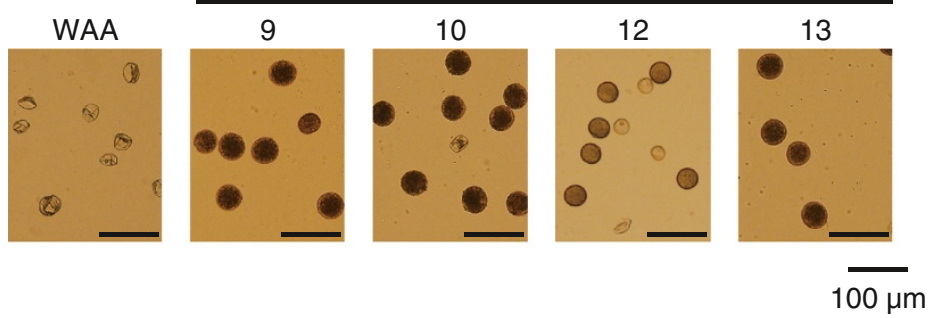

b

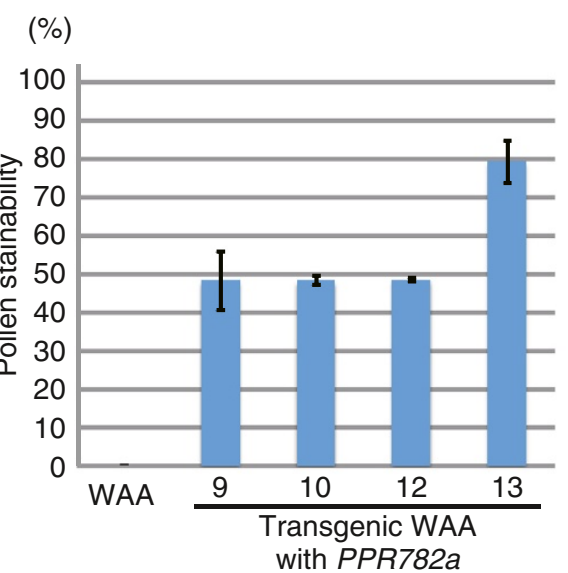

C

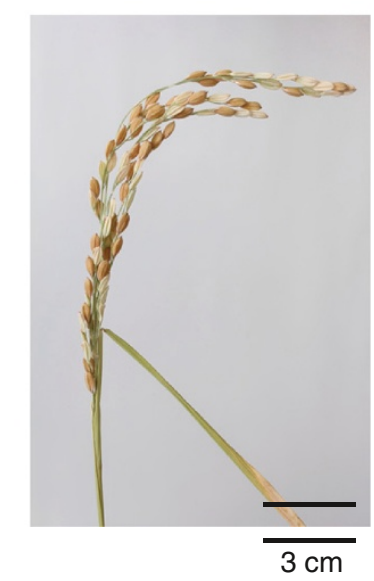

Figure 2 Restoration of fertility in transgenic plants with PPR782a. (a) Pollen grains stained with iodine-potassium iodide. (b) Pollen stainability of each transgenic plant. Error bars indicate the standard deviation. (c) Seed setting of the transgenic plant, No. 13. 


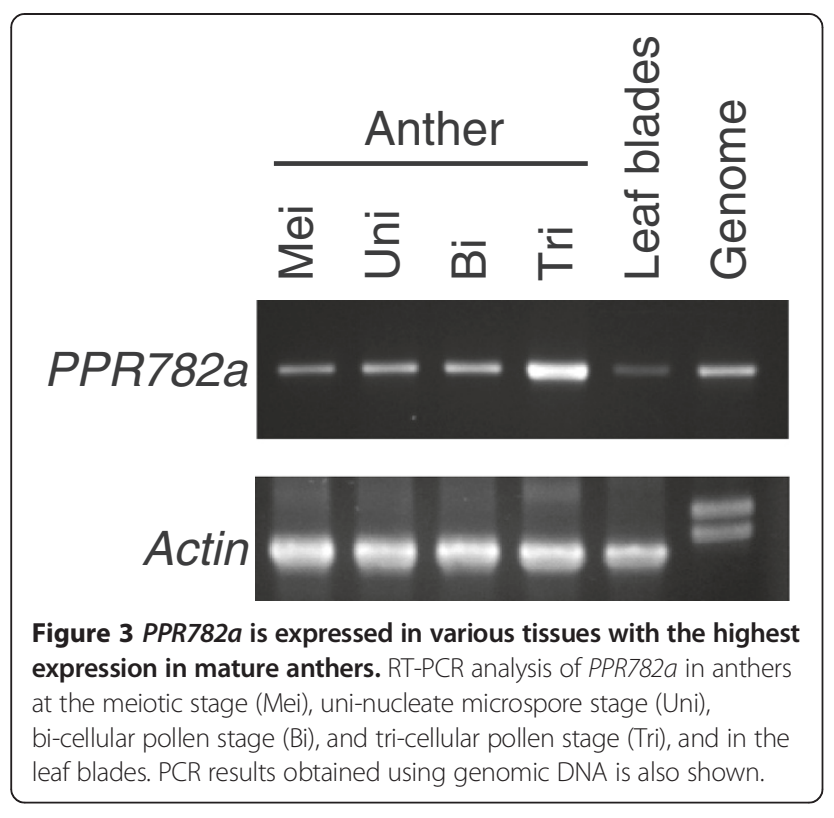

pollen stainability and no seed setting. These data indicate that $R f 4$ is the PPR782a gene.

$\mathrm{T}_{1}$ seeds were set by self-pollination. The progeny segregated into 8 fertile plants, all of which carried the introduced gene, and 7 male-sterile plants, all of which did not carry the introduced gene (Additional file 5: Figure S3). The appearance of null segregants indicated that PPR782a controlled the fertility restoration sporophytically. The pollen fertility was not completely restored by the introduced $R f 4$ gene. Other fertility restorer genes, such as the $R f 3$ gene on chromosome 1 , might be necessary for fully restoration of WA-CMS (Suresh et al. 2012).

The predicted amino acid sequence of PPR782A carries 18 repeats of PPR motif (Additional file 6: Figure S4) and is highly similar to RF1A for BT-CMS showing $86 \%$ identity (Kazama and Toriyama 2003; Akagi et al. 2004; Komori et al. 2004; Kazama et al. 2008). Amino acid identity between PPR782A and PPR782B was 94\%, with

a

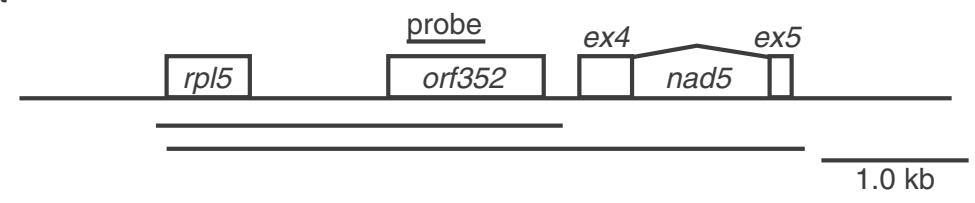

b

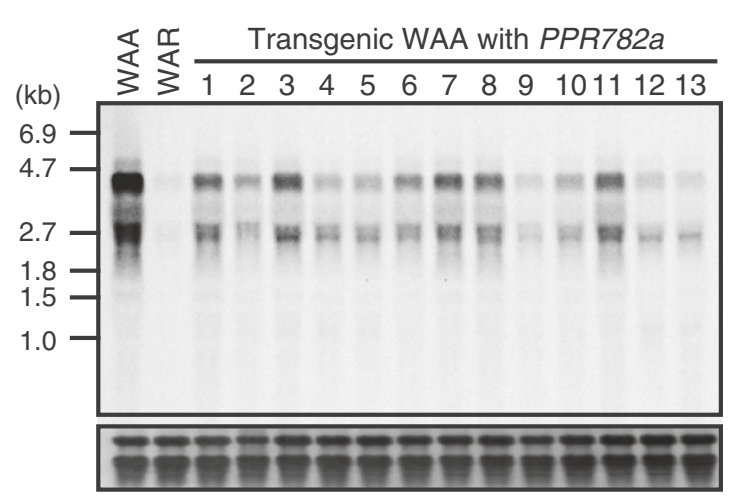

C

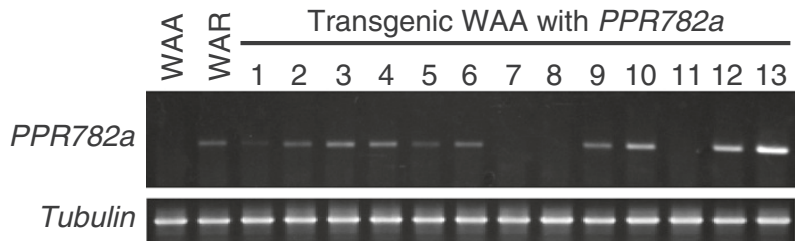

Figure 4 Reduction of orf352-containing RNA in transgenic plants with PPR782a. (a) Genomic structure around orf352 and orf352-containing transcripts. orf352 is located between rp/5 and nad5_exon4_exon5. orf352 is transcribed as both 4.7-kb and 2.5-kb RNA. Horizontal lines represent both transcripts containing orf352. (b) Northern blot analysis of RNA isolated from leaf blades of a cytoplasmic male sterility (CMS) line (WAA), a fertility restorer line (WAR), and transgenic WAA plants with PPR782a. Staining of ribosomal RNA is shown as a loading control. (c) Expression of the introduced PPR782 $a$ and tubulin detected by RT-PCR. 
a completely identical region in the $\mathrm{N}$ - and $\mathrm{C}$-terminal ends. A non-restorer line, Nipponbare, contained a putative allele of PPR782a, which is encoded by the Rice Annotation Project (RAP) locus ID Os10g0495200. The amino acid sequence of PPR782A_Nipponbare shows 95\% identity to that of PPR782A_IR24 (Additional file 6: Figure S4). Some amino acid substitutions might be crucial for the function of the PPR protein, as was reported for other PPR-type $R f$ genes in petunia (Bentolila et al. 2002) and radish (Brown et al. 2003; Desloire et al. 2003; Koizuka et al. 2003).

Expression of Rf4 was assessed using RT-PCR and gene-specific primers (Additional file 1: "Methods"). Rf4 was expressed weakly in leaf blades. Expression was increased in the course of anther development, with the highest levels noted in the anthers at the tri-cellular pollen stage (Figure 3). Rf4 has been proposed to express highly in the tapetum, because the fertility restoration was sporophytically controlled. Our results of expression analysis indicated that $R f 4$ might play a gametophytic role in the maturation of pollen grains after tapetum degradation, as well as a sporophytic role.

In a recent report on the WA-CMS-associated mitochondrial gene, orf352 (WA352), RF4 was proposed to function post-transcriptionally, leading to the degradation of orf352-containing transcripts, half of which were co-transcribed with the upstream gene $r p l 5$ encoding the ribosomal protein large subunit 5 (rpl5-orf352 transcripts; Figure 4a), whereas RF3 acted post-translationally and suppressed translation of orf352 (Luo et al. 2013). To determine whether the cloned Rf4 reduced rpl5-orf352 transcripts, we performed northern blot analysis by using RNA extracted from the leaf blades (Additional file 1: "Methods"). In a WA-CMS plant, WAA, we detected two strong signals of 4.5 - and $2.7-\mathrm{kb}$ bands corresponding to the rpl5-orf352 and orf352 transcripts, respectively (Figure 4b), as reported (Luo et al. 2013). In a fertility restorer line, WAR, the signals of both the bands almost disappeared (Figure 4b). In four transgenic plants (Nos. 9, 10,12 , and 13) showing recovery of anther morphology and pollen stainability, the amount of the two transcripts decreased (lanes 9, 10, 12, and 13; Figure 4b). These four plants showed higher expression of the introduced PPR782a gene as detected by RT-PCR (Figure 4c). Northern blot analyses performed using $\operatorname{cox} 1$ and $a t p 9$ probes revealed that the introduction of PPR782a did not affect the accumulation of these transcripts (Additional file 7: Figure S5). These results suggested that $R f 4$ was involved in the reduction of orf352-containing transcripts.

RF4 is considered to recognize and bind orf352containing transcripts and promote the degradation of orf352-containing transcripts to avoid ORF352-mediated premature programmed cell death and consequent male sterility (Luo et al. 2013). Finding a nuclear $R f$ factor provide novel insights into reconciliation between mitochondria and nuclei in agronomically important crops, and has practical implications for production of hybrid rice.

During preparation of this manuscript, Tang et al. (2014) have reported a short letter entitled as "The rice restorer $R f 4$ for wild-abortive cytoplasmic male sterility encodes a mitochondrial-localized PPR protein that functions in reduction of WA352 transcripts". Their study turned to be essentially the same to ours. They used a PCR-amplified genomic clone of cv. Minghui 63 for a complementation test, but did not investigate the selfpollinated progeny. In contrast, our study used the genomic clones isolated from BAC libraries of IR24 and examined the segregation in the $T_{1}$ plants, showing that the fertility restoration was controlled sporophytically (Additional file 5: Figure S3). The nucleotide sequence of the RF4 allele of IR24 in our study is completely identical to that presented in Supplementary Figure of Tang et al. (2014). An adjacent gene, PPR782b, identified in our study has not been reported in their study. Thus our study is not just a confirmation of Tang et al. (2014), but further provides more information.

\section{Accession codes}

The nucleotide sequences of PPR454, PPR782a, PPR782b, and PPR458 have been deposited at the DDBJ under accession numbers [AB900791 to AB900794].

\section{Additional files}

Additional file 1: Methods. Table S2. Primer Sequences used for RTPCR and probe synthesis for northern blot analysis.

Additional file 2: Table S1. Mapping of Rf4. Primer information used for mapping Rf4 and number of plants in the range of percentage of seed setting in $F_{2}$ plants homozygously carrying Taichung 65 allele at the designated SSR markers.

Additional file 3: Figure S1. Candidate genes (PPR454, $P P R 782 a$ PPR782b and PPR458) and the genomic clones used for the complementation test. The nucleotide sequences are deposited at the DDBJ under accession numbers AB900791, AB900792, AB900793, and AB900794, respectively.

Additional file 4: Figure S2. Restoration of anther morphology in transgenic plants with PPR782a. Anthers of WAA are milky white, slender, and stunted, whereas those of T65 are yellow and engorged. *Number of plants with recovered anther development/number of total transgenic plants is indicated in parenthesis.

Additional file 5: Figure S3. Segregation of fertile and sterile plants in $\mathrm{T}_{1}$ progeny. (a) Segregation of the transgenes (PPR782 $a$ and HPT) in each $T_{1}$ plant obtained by self-pollination of the No. 13 plant. The lowest pane indicates control PCR amplifying tubulin genetic region. Seed setting rates of each $\mathrm{T}_{1}$ plant are shown under the panel. (b) Representative anthers of $\mathrm{T}_{1}$ plants with the introduced PPR782a were yellow and engorged. On the other hand, null segregants produced stunted anthers as those of WAA.

Additional file 6: Figure S4. Amino acid sequence of PPR782A_IR24 aligned with PPR782B_IR24 and Os10g0495200 of Nipponbare. Alignments were performed using ClustalW2.1. The eighteen PPR motifs are included in gray boxes. A mitochondrial targeting signal peptide predicted by MitoProt II is shown in red. 
Additional file 7: Figure S5. Northern blot analysis of cox1 and atp9. RNA was isolated from leaf blades of a CMS line (WAA), a fertility restorer line (WAR), and transgenic WAA plants with PPR782a. Staining of ribosomal RNA is shown as a loading control.

\section{Abbreviations}

BAC: Bacterial artificial chromosome; BT: Boro-Taichung; CMS: Cytoplasmic male sterility; PPR: Pentatricopeptide repeat; RT-PCR: Reverse-transcriptasepolymerase chain reaction; SSR: Simple sequence repeat; WA: Wild abortive.

\section{Competing interests}

The authors declare no potential competing interests.

\section{Authors' contributions}

TK performed the experiments and drafted the manuscript. KT designed and supervised the study and revised the manuscript. Both authors read and approved the final draft of the manuscript.

\section{Acknowledgments}

This work was supported by MEXT/JSPS KAKENHI Grant Numbers 2338002, 24117502 and 26292002, and by Science and technology research promotion program for agriculture, forestry, fisheries and food industry (No. 26010A) and a grant from the Ministry of Agriculture, Forestry and Fisheries of Japan (Genomics-based Technology for Agricultural Improvement, QTL-4008). We thank Dr. Masahiro Yano (National Institute of Agrobiological Sciences, Tsukuba, Japan) for providing BAC clones. The RIL accessions used in this study were obtained from the National Institute of Genetics supported by the National BioResource Project, MEXT, Japan.

Received: 16 June 2014 Accepted: 26 September 2014

Published online: 01 November 2014

\section{References}

Ahmadikhah A, Karlov GI (2006) Molecular mapping of the fertility-restoration gene Rf4 for WA-cytoplasmic male sterility in rice. Plant Breed 125:363-367, doi:10.1111/J.1439-0523.2006.01246.X

Akagi H, Nakamura A, Yokozeki-Misono Y, Inagaki A, Takahashi H, Mori K, Fujimura T (2004) Positional cloning of the rice Rf-1 gene, a restorer of BT-type cytoplasmic male sterility that encodes a mitochondria-targeting PPR protein. Theor Appl Genet 108:1449-1457, doi:10.1007/s00122-004-1591-2

Barclay A (2010) Hybridizing the world. Rice Today 9:32-35

Bentolila S, Alfonso AA, Hanson MR (2002) A pentatricopeptide repeat-containing gene restores fertility to cytoplasmic male-sterile plants. Proc Natl Acad Sci U S A 99:10887-10892, doi:10.1073/Pnas.102301599

Brown GG, Formanova N, Jin H, Wargachuk R, Dendy C, Patil P, Laforest M, Zhang JF, Cheung WY, Landry BS (2003) The radish Rfo restorer gene of Ogura cytoplasmic male sterility encodes a protein with multiple pentatricopeptide repeats. Plant J 35:262-272, doi:10.1046/J.1365-313x.2003.01799.X

Desloire S, Gherbi H, Laloui W, Marhadour S, Clouet V, Cattolico L, Falentin C, Giancola S, Renard M, Budar F, Small I, Caboche M, Delourme R, Bendahmane A (2003) Identification of the fertility restoration locus, Rfo, in radish, as a member of the pentatricopeptide-repeat protein family. EMBO Rep 4:588-594, doi:10.1038/Sj.Embor.Embor848

Jing RC, Li XM, Yi P, Zhu YG (2001) Mapping fertility-restoring genes of rice WA cytoplasmic male sterility using SSLP markers. Bot Bull Acad Sinica 42:167-171

Kazama T, Toriyama K (2003) A pentatricopeptide repeat-containing gene that promotes the processing of aberrant atp6 RNA of cytoplasmic male-sterile rice. FEBS Lett 544:99-102

Kazama T, Nakamura T, Watanabe M, Sugita M, Toriyama K, Kazama T, Nakamura T, Watanabe M, Sugita M, Toriyama K (2008) Suppression mechanism of mitochondrial ORF79 accumulation by Rf1 protein in BT-type cytoplasmic male sterile rice. Plant J 55:619-628, doi:10.1111/j.1365-313X.2008.03529.X

Koizuka N, Imai R, Fujimoto H, Hayakawa T, Kimura Y, Kohno-Murase J, Sakai T, Kawasaki S, Imamura J (2003) Genetic characterization of a pentatricopeptide repeat protein gene, orf687, that restores fertility in the cytoplasmic malesterile Kosena radish. Plant J 34:407-415

Komori T, Ohta S, Murai N, Takakura Y, Kuraya Y, Suzuki S, Hiei Y, Imaseki H, Nitta N (2004) Map-based cloning of a fertility restorer gene, Rf-1, in rice (Oryza sativa L.). Plant J 37:315-325
Li SQ, Yang DC, Zhu YG (2007) Characterization and use of male sterility in hybrid rice breeding. J Integr Plant Biol 49:791-804, doi:10.1111/J.17447909.2007.00513.X

Lu Y, Virmani SS, Zhang G, Bharaj TS, Huang N (1997) Mapping of the Rf-3 nuclear fertility-restoring gene for WA cytoplasmic male sterility in rice using RAPD and RFLP markers. Theor Appl Genet 94:27-33

Luo D, Xu H, Liu Z, Guo J, Li H, Chen L, Fang C, Zhang Q, Bai M, Yao N, Wu H, Wu H, Ji C, Zheng H, Chen Y, Ye S, Li X, Zhao X, Li R, Liu YG (2013) A detrimental mitochondrial-nuclear interaction causes cytoplasmic male sterility in rice. Nat Genet 45:573-577, doi:10.1038/ng.2570

Ngangkham U, Parida SK, De S, Kumar KAR, Singh AK, Singh NK, Mohapatra T (2010) Genic markers for wild abortive (WA) cytoplasm based male sterility and its fertility restoration in rice. Mol Breed 26:275-292, doi:10.1007/ S11032-010-9397-1

Okazaki M, Kazama T, Murata H, Motomura K, Toriyama K (2013) Whole mitochondrial genome sequencing and transcriptional analysis to uncover an RT102-type cytoplasmic male sterility-associated candidate gene derived from Oryza rufipogon. Plant Cell Physiol 54:1560-1568, doi: 10.1093/pcp/ pct102

Schmitz-Linneweber C, Small I (2008) Pentatricopeptide repeat proteins: a socket set for organelle gene expression. Trends Plant Sci 13:663-670, doi:10.1016/ j.tplants.2008.10.001

Suresh PB, Srikanth B, Kishore VH, Rao IS, Vemireddy LR, Dharika N, Sundaram RM, Ramesha MS, Rao KRSS, Viraktamath BC, Neeraja CN (2012) Fine mapping of $R f 3$ and Rf4 fertility restorer loci of WA-CMS of rice (Oryza sativa L.) and validation of the developed marker system for identification of restorer lines. Euphytica 187:421-435, doi:10.1007/S10681-012-0737-6

Tan YP, Li SQ, Wang L, Liu G, Hu J, Zhu YG (2008) Genetic analysis of fertility-restorer genes in rice. Biologia Planta 52:469-474, doi:10.1007/S10535-008-0092-6

Tang H, Luo D, Zhou D, Zhang Q, Tian D, Zheng X, Chen L, Liu YG (2014) The Rice Restorer Rf4 for wild-abortive cytoplasmic male sterility encodes a PPR protein that functions in reduction of WA352 transcripts. Mol Plant 7:1497-1500, doi:10.1093/mp/ssu047

Yao FY, Xu CG, YU SB, Li JX, Gao YJ, Li XH, Zhang QF (1997) Mapping and genetic analysis of two fertility restorer loci in the wild-abortive cytoplasmic male sterility system of rice (Oryza sativa L.). Euphytica 98:183-187, doi:10.1023/ A:1003165116059

doi:10.1186/s12284-014-0028-z

Cite this article as: Kazama and Toriyama: A fertility restorer gene, Rf4, widely used for hybrid rice breeding encodes a pentatricopeptide repeat protein. Rice 2014 7:28.

\section{Submit your manuscript to a SpringerOpen ${ }^{\odot}$ journal and benefit from:}

- Convenient online submission

- Rigorous peer review

- Immediate publication on acceptance

- Open access: articles freely available online

- High visibility within the field

- Retaining the copyright to your article

Submit your next manuscript at $\gg$ springeropen.com 